\title{
Halogen Occultation Experiment (HALOE) and balloon-borne in situ measurements of methane in stratosphere and their relation to the quasi-biennial oscillation (QBO)
}

\author{
P. K. Patra ${ }^{1}$, S. Lal ${ }^{2}$, S. Venkataramani ${ }^{2}$, and D. Chand ${ }^{3}$ \\ ${ }^{1}$ Frontier Research System for Global Change, Yokohama 236 0001, Japan \\ ${ }^{2}$ Physical Research Laboratory, Ahmedabad 380 009, India \\ ${ }^{3}$ Max Planck Institute for Chemistry, 55020 Mainz, Germany \\ Received: 24 February 2003 - Published in Atmos. Chem. Phys. Discuss.: 14 April 2003 \\ Revised: 25 June 2003 - Accepted: 10 July 2003 - Published: 16 July 2003
}

\begin{abstract}
Measurements of methane have been made from various observational platforms in the atmosphere. In this article, we have compared four high precision balloon-borne measurements from Hyderabad $\left(17.5^{\circ} \mathrm{N}\right)$, India in the period of 1987 and 1998 with a part of HALOE/UARS global observations available since 1991. All the balloon measurements correspond to boreal spring (March and April) but belong to different years. A comparison shows fairly good agreement with each other. The gradient in $\mathrm{CH}_{4}$ profiles in the troposphere is controlled by the variation in vertical transport. The strongest effect of dynamical influence on methane vertical profiles is shown to be resulting from the dynamical quasi-biennial oscillation in the stratosphere, and that has been consistently derived from both the measurement techniques and chemistry-transport model simulations. It is observed that the QBO signal in $\mathrm{CH}_{4}$ anomaly exhibits interhemispheric asymmetry caused by the tropics to midlatitude circulation in the stratosphere. A mechanism is suggested to explain how and to what extent the methane vertical profiles over Hyderabad and higher latitudes could be modulated by the prevailing QBO winds in the tropics. We have also discussed how the same mechanism would affect ozone distribution in the stratosphere quite differently.
\end{abstract}

\section{Introduction}

Methane $\left(\mathrm{CH}_{4}\right)$ plays important role in chemistry and radiative balance of the lower and middle atmosphere. It has been estimated that typically about $97 \%$ of $\mathrm{CH}_{4}$ oxidation by $\mathrm{OH}$ takes place in the troposphere (Lawrence et al., 2001), and this gas generates 20 times more radiative forcing compared to that of $\mathrm{CO}_{2}$ on a per molecule basis (IPCC, 1996). In the stratosphere chemical reactions with $\mathrm{O}^{1} \mathrm{D}$ and $\mathrm{Cl}$ dominate $\mathrm{CH}_{4}$ destruction. Its abundance has increased rapidly since

Correspondence to: P. K. Patra (prabir@jamstec.go.jp) the 1950s to the present day (Etheridge et al., 1998). However, from the beginning of 1990s a dramatic decline in $\mathrm{CH}_{4}$ increase rate has been observed globally (Dlugokencky et al., 2001). Since its emission rate is changing very slowly and its total photochemical loss rate in the lower/middle stratosphere is quite small, anomalies in its stratospheric distribution bear footprints of dynamics, such as quasi-biennial, annual and semi-annual oscillations etc. (see Baldwin et al., 2001, for a review). It is established that the QBO constitutes a major part of the variabilities in $\mathrm{CH}_{4}$ and $\mathrm{O}_{3}$ anomaly with a time period of about 27-30 months in the stratosphere (Tung and Yang, 1994; Randel et al., 1998). The QBO phase in $\mathrm{O}_{3}$ anomaly changes at around $15^{\circ}$ on either side of the equator and the higher latitude anomaly extends as deep as $60^{\circ}$ latitude (Randel and $\mathrm{Wu}, 1996$ ). However, the latitudinal extent and interhemispheric differences of QBO influence on $\mathrm{CH}_{4}$ anomaly have not been very well understood due to shorter temporal coverage of data on the record. Only recently, extensive discussions on observations of the QBO in HALOE $\mathrm{CH}_{4}$ have been made (Ruth et al., 1997; Randel et al., 1998; Dunkerton, 2001). Two-dimensional (2D) chemistry-transport-radiation models of the stratosphere based on analysed meteorological parameters (e.g. winds, temperature) are being used to simulate the derived interannual variations from the satellite measurements of $\mathrm{CH}_{4}, \mathrm{O}_{3}$, $\mathrm{H}_{2} \mathrm{O}$ etc. (e.g Fleming et al., 2002; McCormak and Siskind, 2002). Their sensitivity tests are useful to visualize the effects of dynamical QBO and temperature QBO on trace gas distribution, or to study the role planetary wave amplitude on QBO periodicity. Here we take advantage of some of these understandings in the explanation of observed features in $\mathrm{CH}_{4}$ distributions over a tropical site in India.

The measurements of $\mathrm{CH}_{4}$ in the stratosphere have been started with the advent of appropriate technology, and records are available since the early 1970s by using balloonborne cryogenic collection of air samples (Ehhalt, 1980; Fabian, 1981), and from the satellite platforms only during

(C) European Geosciences Union 2003 
the past two decades (Jones and Pyle, 1984; Russell et al., 1993). But quality $\mathrm{CH}_{4}$ data from a tropical latitude using balloons, and more frequently by the satellite are available since about past 15 and 10 years, respectively (Borchers et al., 1989; Russell et al., 1993; Lal et al., 1994, 1996). These observations provide us a unique opportunity to compare two different kinds of dataset spreading over a decade, coverring about 4 complete QBO cycles. The satellite data sets are also being utilized extensively to study the influence of various dynamical, and chemical composition changes in the stratosphere. However, no significant usage of satellite observations together with in situ measurements in lower and middle stratosphere could be found in the literature. It could also be noted that though there have been some discussion on the differences in behaviour of vertical distribution of long-lived gases over Hyderabad, India (Lal et al., 1996; Patra et al., 1997, 2000), no detailed study has been carried out so far.

Here we have attempted to find possible cause for the differences in the vertical profiles observed over the tropics using balloon-borne techniques during March-April period of four different years that are well separated by an interval of about 4 years. The satellite observations and 2-D model simulations over this location and its dynamical neighbourhood are used to support our findings. In the next section details about the data sources and analysis procedure are given, followed by the results and discussion section. The major conclusions of this study are listed in Sect. 4.

\section{Data and Analysis}

In the period of 1987 to 1998, four balloon flights have been conducted from the National Balloon-launching Facility (NBF) at Hyderabad $\left(17.5^{\circ} \mathrm{N}, 78.6^{\circ} \mathrm{E}\right)$, India on (1) 27 March 1987, (2) 9 April 1990, (3) 16 April 1994, and (4) 18 April 1998. The first two balloon flights were conducted jointly by Max Planck Institute for Aeronomy (MPAE), Lindau and Physical Research Laboratory (PRL), and the latter two flights by PRL only. The payload (balloon gondola) containing a 16-tube cyro-sampler along with its control unit were flown with the help of large volume $\left(\sim 150000 \mathrm{~m}^{3}\right)$ Pyrex rubber balloon filled with hydrogen gas. The ambient air samples were collected at 15 separate altitudes in the upper troposphere and stratosphere during both ascent and descent of the balloon. Typically, a ceiling altitude of about $35 \mathrm{~km}$ was attained during the experiments. The sampling tubes were then brought to the laboratory and analysed for several chemical constituents using GCs coupled with flame ionization detector (for $\mathrm{CH}_{4}$ and $\mathrm{CO}$ ), electron capture detector $\left(\mathrm{SF}_{6}, \mathrm{~N}_{2} \mathrm{O}\right.$, chlofluorocarbons, Halons etc.) and mass spectroscopy (for hydrogenated halocarbons). The calibration for absolute concentration of $\mathrm{CH}_{4}$ was done with respect to the standard gases supplied by Linde gas, UK and NIST, USA. The precision of GC analyses is estimated to be within 5 ppbv $(1 \sigma)$, and the errors in absolute concentration are es- timated to be in the range of $2-3 \%(1 \sigma)$. The results from these balloon flights have been published earlier (Borchers et al., 1989; Lal et al., 1996; Patra et al., 2000; Lal and Sheel, 2000), but no systematic comparison has been made so far in terms of interannual variations and with satellite data.

The vertical profiles of $\mathrm{CH}_{4}$, constructed from 4 different balloon flight experiments during boreal spring at an interval of about four years, are shown in Fig. 1a. As argued using the stratospheric measurements of $\mathrm{SF}_{6}$ over India in a previous study (Patra et al., 1997), the dynamical condition on the measurement day of 16 April 1994 represents a normal day at $17.5^{\circ} \mathrm{N}$, that is typical of the tropical stratosphere (hereinafter referred to as "normal" profiles). The 1994 profiles of $\mathrm{SF}_{6}, \mathrm{~N}_{2} \mathrm{O}, \mathrm{CF}_{2} \mathrm{Cl}_{2}$ etc. also match fairly well with two-dimensional model simulations (Patra et al., 1997, 2000). The location of the measurement station is subtle in a sense that the tropical upwelling region in stratosphere is located over Hyderabad during northern hemisphere $(\mathrm{NH})$ summer (May-June-July), and in NH winter (DecemberJanuary-February) the upwelling region moves to the southern hemisphere (SH). Thus sometimes the balloon travelled close to the stratospheric "surf zone", and measured vertical distributions often deviate from the normal profile. The observations on 27 March 1987 and 9 April 1990 are the examples of disturbed profiles from the "normal" profile. It can be noted that the magnitude of deviation as well as the altitude of occurrence could vary largely with time. The characteristics of the profile observed on 18 April 1998 exhibit a relatively better match with the 1994 profile compared to the other two. This also suggests that the transition from winter to summer in the stratosphere takes place during late March to early April period at $17.5^{\circ} \mathrm{N}$. We have checked the horizontal distributions of monthly mean geopotential heights (z) from the NCEP/NCAR reanalysis datasets (Kistler et al., 2001), which commonly show that the gradient in $z$ starts around $30^{\circ} \mathrm{N}$ in April at $50 \mathrm{mb}$ height. This behaviour of $z$ was quite similar at $10 \mathrm{mb}$ pressure layer during April. However, in March the location of $z$ gradient region shifts over to lower latitudes and lies over Hyderabad.

Figure $1 \mathrm{~b}$ shows the zonal wind component as obtained from the NCEP/NCAR reanalysis at Hyderabad. It is wellknown that the distribution of $\mathrm{CH}_{4}$ in the free troposphere (above the planetary boundary layer) is rather well-mixed and does not depend on local dynamics to a large extent. Thus the mixing ratios of $\mathrm{CH}_{4}$ in the middle troposphere region $(\sim 6-12 \mathrm{~km})$ do not deviate significantly (less than $10 \%$ ) from one another with time. More discussions on tropospheric data are given in a latter section. The main features in this plot are observed at the stratospheric heights: 1) The 1994 profile is uniformly higher in methane above $20 \mathrm{~km}$ than other profiles - from the wind profiles it is seen that magnitude of easterly winds (also the easterly wind shear) was maximum in 1994 compared to other years of measurements. 2) This also readily shows that the mixing ratio minimum in 1990 around $25-33 \mathrm{~km}$ layer is related to 


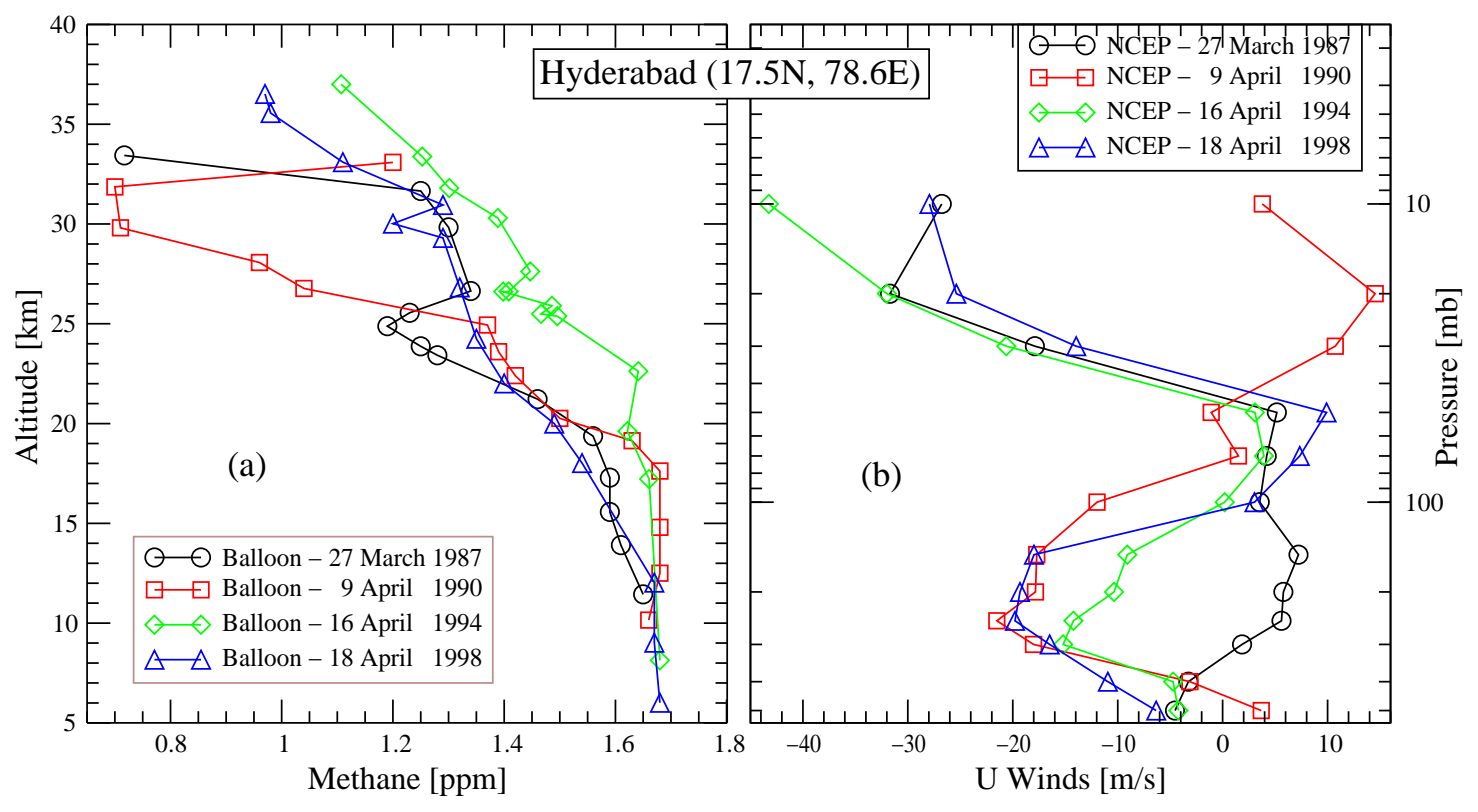

Fig. 1. Vertical profiles of $\mathrm{CH}_{4}$ obtained by analyzing the ambient air collected during the cryo-sampler experiments in boreal spring of 1987 , 1990, 1994 and 1998 (a, left panel). The 1987 and 1990 profiles are obtained from the PRL-MPAE collaborative programme (Borchers et al., 1989), and 1994 and 1998 profiles are from the PRL conducted experiments (Lal et al., 1996). On the right panel (b) vertical profiles of zonal winds from the NCEP/NCAR reanalysis, corresponding to Hyderabad $\left(17.5^{\circ} \mathrm{N}, 77.5^{\circ} \mathrm{E}\right)$, are depicted.

the westerly wind shear and downwelling in the deep tropics and subtropics as $\mathrm{CH}_{4}$ concentration decreases upward. The increase in $\mathrm{CH}_{4}$ above $32 \mathrm{~km}$ in 1990 is probably related to lofting in QBO easterly wind shear regime; indication of strong easterly shear in the wind profile is appearing above $27 \mathrm{~km}$. 3) In 1987 the minimum in methane near $20-26 \mathrm{~km}$ should be related to a westerly wind shear regime and downwelling, but is not very clear from the zonal wind diagram. Then there appears to be lofting in the easterly shear zone and the reversal in wind shear above $30 \mathrm{~km}$ seem to be causing the very low $\mathrm{CH}_{4}$ concentration at $33 \mathrm{~km}$. In addition to the changes in vertical transport in different zonal wind regimes, the secondary meridional circulation (Choi et al., 2002) can also contribute to the low $\mathrm{CH}_{4}$ values in the vertical profiles.

At the same time, global coverage of several chemical constituents are available since the launch of HALogen Occultation Experiment (HALOE) onboard the Upper Atmosphere Research Satellite (UARS) in September 1991. Though the UARS mission itself began with an expected lifetime of about 2-3 years, this satellite and many of the instruments onboard continues to make equally good quality measurements (as of April 2003). The datasets are being used for various other kinds of study; e.g. deriving trends in $\mathrm{CH}_{4}$ in the stratosphere, timeseries correlation of $\mathrm{CH}_{4}$ with other constituents such as $\mathrm{ClO}_{x}$, and also to create four dimensional regular grid tracer distributions (Froidevaux et al., 2000; Patra and Santhanam, 2001). For comparison with the balloonborne measurements of $\mathrm{CH}_{4}$, we have created the represen- tative vertical profiles for Hyderabad during March-April months in the complete HALOE operation period. First the HALOE $\mathrm{CH}_{4}$ profiles (Level 2, SPF formatted, both sunrise and sunset), observed between 15 March-15 April of each year and in the $16-19^{\circ} \mathrm{N}$ latitude band (Hyderabad location $\pm 1.5^{\circ}$ ), are selected and the values are interpolated to 30 pressure levels in the height region of $100.0-1.0 \mathrm{mb}$. Then $\mathrm{CH}_{4}$ concentrations at each pressure level are averaged to produce one vertical profile representing the boreal spring of each calendar year, which are depicted on Fig. 2 (error bars, $1 \sigma$, are also shown). While the average values depict the interannual variations in $\mathrm{CH}_{4}$ distributions, the spread of the error bars indicate the variability in observed concentrations during March/April months of a particular year. It is apparent from the diagram that depending on dynamical condition in our study region, the characteristics of the vertical profiles change from year to year. For instance, the 1997 and 2001 profiles show clear deviation from the other profiles by an amount larger than the error bars, and also the altitude of maximum deviation lies in the range of $25-35 \mathrm{~km}$. The 1995 and 1993 profiles also show discernible difference from the normal profiles, though the intensities and altitude regions are different. We have also used the 4-dimensional $\mathrm{CH}_{4}$ dataset produced by Patra and Santhanam (2001) later in this work.

It is well-known that the long-lived trace gases (e.g. $\mathrm{CH}_{4}$, $\mathrm{N}_{2} \mathrm{O}, \mathrm{O}_{3}$ ) and aerosol distributions in the stratosphere are closely linked with zonal wind variations in the tropics 

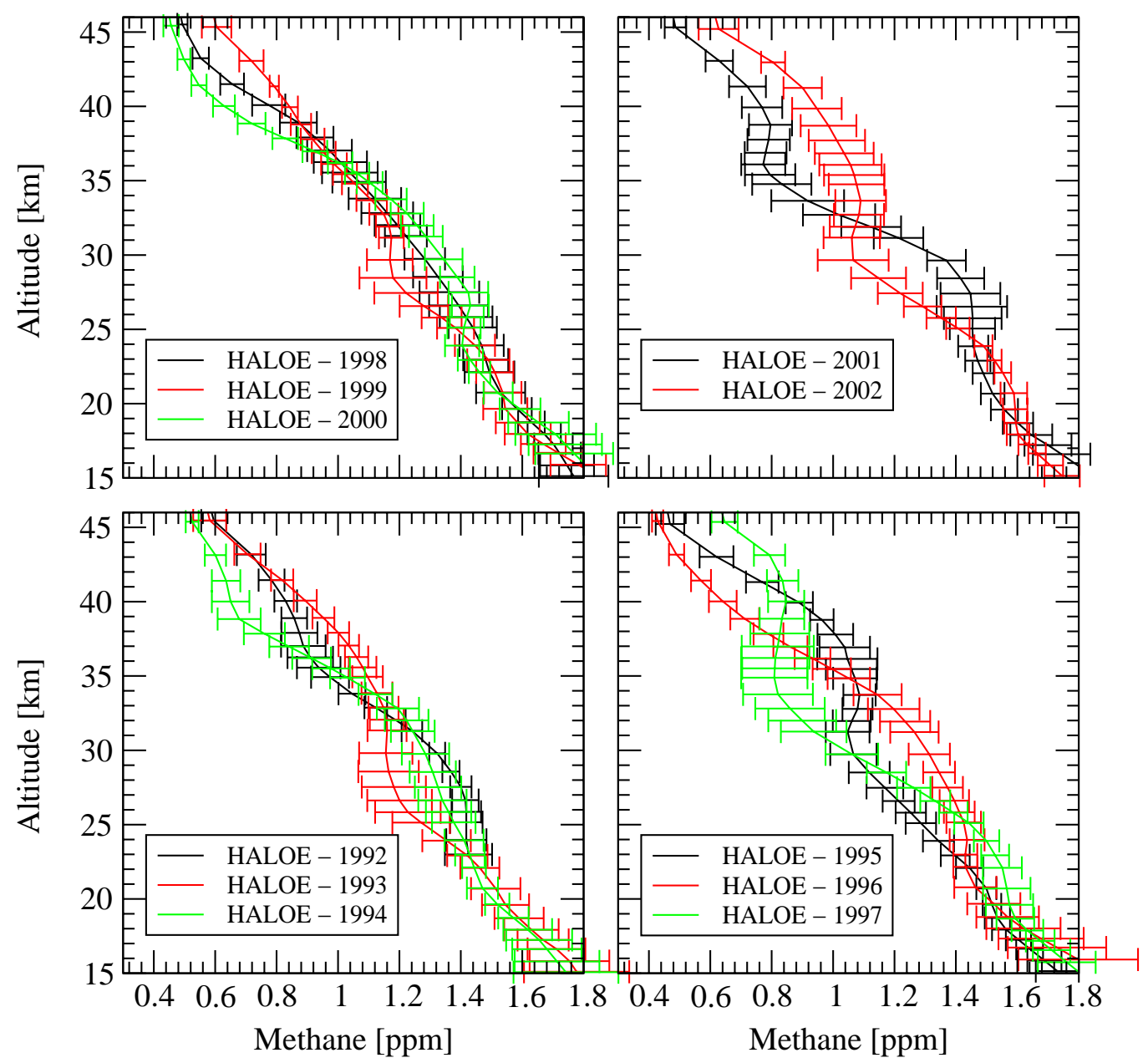

Fig. 2. Observed HALOE $\mathrm{CH}_{4}$ profiles during 15 March-15 April of each year in the period of HALOE operation. All the available (sunset and sunrise both) profiles in the latitude $17.5 \pm 1.5^{\circ} \mathrm{N}$ band are averaged.

(Tung and Yang, 1994; Hitchman et al., 1994; Randel et al., 1998; Jones et al., 1998). Some studies also highlighted the interaction between seasonal, subennial and quasi-biennial oscillations in the meteorological parameters to explain the observed variations in $\mathrm{CH}_{4}$ (Ruth et al., 1997; Dunkerton, 2001). In Fig. 3, we show the altitude-time variation of zonal winds anomaly in the period of 1985 and 2002 as revealed from the NCEP/NCAR reanalysis data (Huesmann and Hitchman, 2001). This diagram shows the temporal extent and altitude distribution of QBO phase and intensity at the equator. As it is discussed above only two out of four balloon-borne observations of $\mathrm{CH}_{4}$ have overlapping measurements using HALOE. To compare the balloon data with satellite observations, we have identified the QBO phases from this diagram that year 2001 and 1997 closely match with 1987 and 1990 boreal spring conditions, respectively. This search was needed because the QBO is an irregular oscillation, and its period has averaged about 30 months in the period of 1980-1992 and averaged about 27 months in the earlier decades (Tung and Yang, 1994). In addition the QBO and annual cycle are known to have interplay that influence the constituent transport and distribution due to upwelling motion in the equatorial lower stratosphere (Mote et al., 1996; Hinsta et al., 1998). During this selection process, the observed vertical profiles of $\mathrm{CH}_{4}$ from Hyderbad were also kept in mind to ensure the best possible suitability.

\section{Results and Discussion}

In Fig. 4 a comparison of $\mathrm{CH}_{4}$ vertical profiles obtained from the balloon-borne measurements and the satellite observations are shown. Also shown are the NASA/Goddard Space Flight Center (GSFC) 2-D chemistry-transport model simulations (Fleming et al., 2002) for the corresponding balloon flight dates. The treatments of chemistry, meteorology and radiation in the GSFC 2-D model can be found in Fleming et al. (2002) and references therein. It uses interannually varying meteorological conditions (winds and temperature) based 


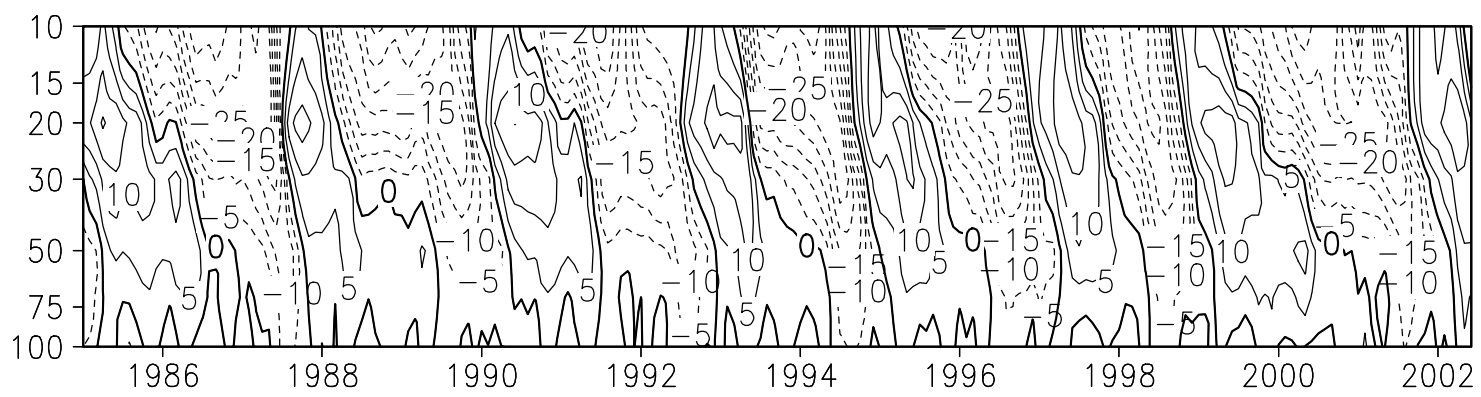

Fig. 3. Temporal variations in monthly mean zonal wind anomalies $(\mathrm{m} / \mathrm{s})$ with respect to pressure (mb), produced by the NCEP/NCAR reanalysis project over the equator. The contour interval is $5 \mathrm{~m} / \mathrm{s}$; negative wind speed represents the easterlies (denoted by dotted lines), and the Westerly phase of QBO is seen as the positive winds (solid lines). Note that the height extent of QBO is approximately from 100 mb to $10 \mathrm{mb}$, and above $3 \mathrm{mb}$ (not shown here due to the lack of NCEP/NCAR reanalysis data beyond $10 \mathrm{mb}$ height) dominance of the semi-annual oscillation (SAO, westerly near the equinox and easterly near the solstice) over QBO is apparent (Swinbank and O'Neill, 1994).

on the 3-D UKMO (UK Meteorological Office) assimilated fields in the stratosphere for the period 1992-2000. Since this model has interannual transport variability during 1994 and 1998 balloon flight periods, it is seen that the comparison between the model and observations improves significantly. While the HALOE and balloon $\mathrm{CH}_{4}$ profiles match very well with the 2-D model results in 1998, during 1994 the model simulation compares better with the HALOE measurements. Apparently, the balloon observations overestimate the $\mathrm{CH}_{4}$ values in the stratosphere. The model simulations for 1987 and 1990 periods do not have any features resulting from interannual variability in transport and only accounts for the photochemical loss of $\mathrm{CH}_{4}$ that give rise to monotonous decrease in mixing ratio with altitude. Thus the model simulations do not compare well with the observations from both the platforms.

Since the HALOE observations were nonexistent before 1991, we have used 2001 and 1997 HALOE profiles, respectively, corresponding to the balloon observations in 1987 and 1990 following the discussion in the previous section. We choose to show the best possible matches between the disturbed in situ measurements of $\mathrm{CH}_{4}$ from Hyderabad on March 1987 and April 1990, and the profiles from HALOE data. For the simultaneous measurement periods in 1994 and 1998, the profiles of HALOE $\mathrm{CH}_{4}$ in the latitude band of $17.5 \pm 1.5^{\circ}$ are presented. The $\mathrm{CH}_{4}$ concentrations in the middle troposphere are found to be about $1.65,1.67,1.68$, 1.68 ppmv, from the balloon measurements, respectively, for the years 1987, 1990, 1994, and 1998 (ref. Fig. 1). On a few occasions similar concentrations are also found in the upper troposphere and lower stratosphere (UT/LS) region due to intense upwelling in the upper troposphere and across the tropical tropopause. It can be noticed here that the $\mathrm{CH}_{4}$ increase rate in middle troposphere has been fairly stabilized in the period of 1990-1998, which agrees well with the observations on the ground (Dlugokencky et al., 2001). Further analysis suggest that the $\mathrm{CH}_{4}$ concentrations across the tropopause (at $\sim 17 \mathrm{~km}$ or $100 \mathrm{mb}$ ) generally do not exhibit detectable
Table 1. Slopes in $\mathrm{CH}_{4}$ mixing ratios between the middle troposphere and near the tropopause as derived from the vertical profiles for different years. The relative humidity $(\mathrm{RH})$ and omega $(\Omega)$ for vertical velocity values are given as the monthly means for the global tropics $\left(20^{\circ} \mathrm{S}\right.$ to $\left.20^{\circ} \mathrm{N}\right)$ from the NCEP/NCAR reanalysed dataset.

\begin{tabular}{cccc}
\hline \multirow{2}{*}{$\begin{array}{c}\text { Year of } \\
\text { Measurements }\end{array}$} & \multirow{2}{*}{$\begin{array}{c}\text { Slope } \\
\text { (ppm) }\end{array}$} & \multicolumn{2}{c}{ Monthly Means (Mar/Apr) } \\
\cline { 3 - 4 } & & RH (in \%) & $\Omega($ in Pa/sec) \\
\hline 1987 & 0.06 & $46 / 47$ & $-0.004 /-0.004$ \\
1990 & -0.02 & $55 / 55$ & $-0.005 /-0.003^{*}$ \\
1994 & 0.02 & $50 / 51$ & $-0.005 /-0.005$ \\
1998 & 0.12 & $41 / 42$ & $-0.004 /-0.003$ \\
\hline
\end{tabular}

* is the only outlier in this correlation analysis.

gradients with height. However, relatively faster decrease in $\mathrm{CH}_{4}$ mixing ratios can be found in the upper troposphere region during 1987 and 1998. This decrease can be attributed to the slower vertically upward transport rates during 1987 and 1998 compared to that during 1990 and 1994. The NCEP/NCAR reanalyses data show higher relative humidity and faster vertical transport parameter (Omega, $\Omega$ ) during March/April of 1990 and 1994 relative to March/April of 1987 and 1998 (see Table 1 for details). The anti-correlation between the slopes in $\mathrm{CH}_{4}$ mixing ratios from middle troposphere to the tropopause with relative humidity at $300 \mathrm{mb}$ is very compact (correlation coefficient, $\mathrm{R}^{2}=0.99$ ). Similar correlations with Omega also produce compact linear relationships.

The magnitude of $\mathrm{CH}_{4}$ mixing ratio variation are much larger in the middle stratospheric altitudes. The $\mathrm{CH}_{4}$ concentrations at around $30-32 \mathrm{~km}$ altitude in 1990 and at $34 \mathrm{~km}$ in 1987 are only about 60\% of those observed in 1994 and 1998 in the same altitude regions. Such large changes cannot be explained by the changes in atmospheric $\mathrm{CH}_{4}$ burden, solar irradiance variations, or shifts in the abundances of reactive 

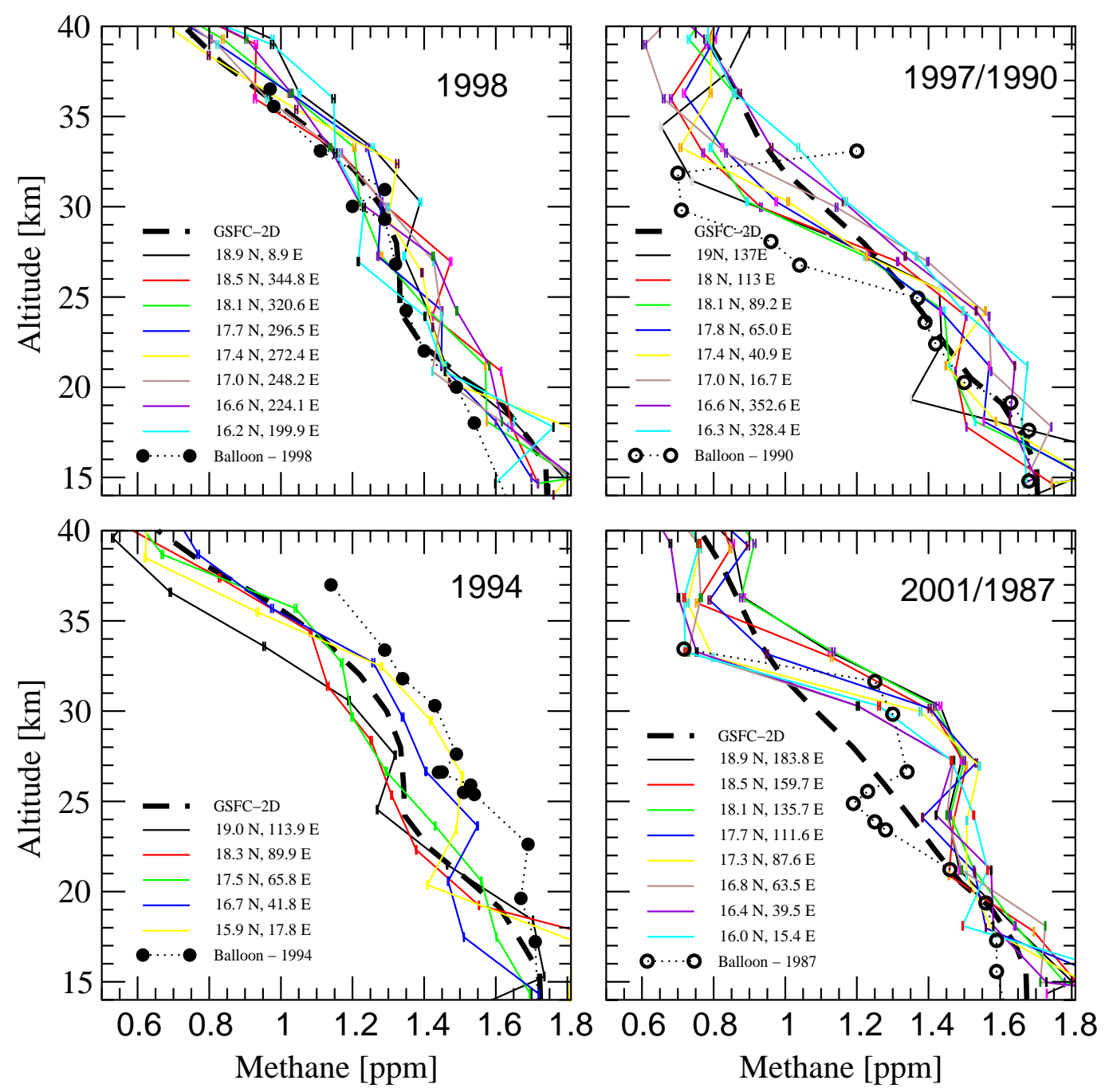

Fig. 4. The overplots of the remote sensing and in situ measurements of $\mathrm{CH}_{4}$ are shown for different periods. The GSFC 2-D model simulations are also shown (thick dashed line) for a comparison. The comparisons of 1994 and 1998 balloon measurements (filled circle) with the HALOE $\mathrm{CH}_{4}$ profiles are shown as they were observed in the respective years (panels on the left). Whereas for 1987 and 1990 balloon data (open circle), we have chosen the HALOE profiles from the years 2001 and 1997, respectively, for comparison (right panels) due to the lack of contemporaneous HALOE measurements, which are selected based on the meteorology of the stratosphere. The time and type of all HALOE measurements can be designated as: 1) 5 April (22:17 GMT) to 6 April (04:43 GMT) in 1994 (Sunrise), 2) 12 April (17:36 GMT) to 13 April 04:50 GMT) in 1998 (Sunset), 3) 17 April (09:03-20:17 GMT) in 1997 (Sunset), and 4) 27 March (05:5217:05 GMT) in 2001 (Sunset). The HALOE profiles are chosen as close to balloon measurement dates as possible irrespective of sunset or sunrise data retrieval.

radicals in the stratosphere (i.e. chemistry). It is also apparent that such events are not rare in this part of the tropical stratosphere, and are captured by the satellite measurements quite frequently, which has finer temporal resolution. Here we argue that the dynamical conditions over Hyderabad in March-April 2001 and 1997 were fairly similar to those experienced during the balloon-borne experiments in March 1987 and April 1990, respectively, based on the zonal wind distribution in the stratosphere. This comparison between the balloon and satellite measurements is shown in Fig. 4. On this diagram individual profiles observed by the HALOE are shown; because earlier studies have suggested that the monsoon structures in the upper troposphere could impose zonal asymmetries in lower $15-20 \mathrm{~km}$ of the stratosphere, while above that level quasi-stationary planetary waves can cause zonal asymmetries in the meteorological fields (e.g. Quiroz et al., 1975). As seen from the legends, the HALOE observations had large zonal coverage within a day in a narrow latitude band. However, no gross feature could be extracted in order to find any zonal asymmetry in the $\mathrm{CH}_{4}$ distributions. In general, the balloon measurement closely matches with the HALOE observations, except in 1994, when the balloon 
observed $\mathrm{CH}_{4}$ mixing ratios are higher by $10-15 \%$ than an average HALOE profile at all altitudes. Even though for 1987 and 1990 balloon measurements there are no contemporaneous HALOE observations, the matches between two compared datasets for different years are unexpectedly good. The HALOE observations in 2001 and 1997 reproduce the $\mathrm{CH}_{4}$ concentrations at most altitudes and successfully capture the low values at $34 \mathrm{~km}$ in 1987 and around $30-32 \mathrm{~km}$ in 1990 balloon data, respectively. The HALOE $\mathrm{CH}_{4}$ observations in 2001 also have a tendency to create a kink at $25 \mathrm{~km}$, similar to that could be seen more prominently in 1987 balloon profile.

The obvious next step is to relate the observed $\mathrm{CH}_{4}$ anomalies with the known dynamical oscillations of the tropical stratosphere, the QBO being the most dominant one. It should be made clear that the rest of the study uses the 4dimensional $\mathrm{CH}_{4}$ distribution produced by Patra and Santhanam (2001). In Fig. 5, the time-height crosssections of $\mathrm{CH}_{4}$ anomalies are plotted at four latitudes $\left(5^{\circ}, 15^{\circ}, 25^{\circ}\right.$, $35^{\circ}$ ) in both the hemispheres. An oscillation in the $\mathrm{CH}_{4}$ anomalies with similar time period like that of the QBO $(\sim 27$ months) can be seen in the whole height range of tropical stratosphere. The most surprising finding is the latitudinal extent of the QBO features in $\mathrm{CH}_{4}$ anomalies, which is in contrast to the presence of in-phase $\mathrm{QBO}$ signals in the zonal winds as well as in ozone distribution; that generally is restricted to about $15^{\circ}$ on either side of the equator (Swinbank and O'Neill, 1994; Baldwin et al., 2001). The panels in Fig. 5 suggest that the height distribution of phase propagation of $\mathrm{CH}_{4}$ anomaly (ascending in nature) to be opposite in phase with the zonal wind anomaly (descending). Another possible explanation for this is the difference in QBO winds effect on transport of long-lived trace constituents from the tropical stratosphere to the higher latitudes through the secondary meridional transport (Choi et al., 2002). It has also been shown in a previous study that the descending westerlies in the tropics enhance transport out of the tropics in the lower stratosphere, whereas the descending easterly winds enhance such transport in the middle stratosphere (Jones et al., 1998). Because the descending limbs of zonal wind anomalies are already out-of-phase to a great extent by about 14 months between the lower (e.g. $50 \mathrm{mb}$ or $\sim 20 \mathrm{~km}$ ) and middle (e.g. $5 \mathrm{mb}$ or $\sim 35 \mathrm{~km}$ ) stratosphere near the equator, and the "out of the tropics" transport acts oppositely in the two QBO wind regimes. It could be possible to draw a changeover line at around $8 \mathrm{mb}$ for this regime shift from the time-height plots of $\mathrm{CH}_{4}$ anomalies (see Fig. 5). It may be relevant to point out here that the Fig. 5 is quite similar to the time-height plot of water vapour anomaly in the stratosphere, depicting the "tape recorder effect" (Mote et al., 1996); except there is an important difference that the variation of water vapour in stratosphere is closely linked to the entrainment of dry and wet tropospheric air through the tropical tropopause, and has a periodicity of about a year. The modelling studies illustrate the differences between the QBO in $\mathrm{CH}_{4}$ and $\mathrm{H}_{2} \mathrm{O}$ distri- butions in the lower stratosphere (McCormak and Siskind, 2002).

The $\mathrm{CH}_{4}$ anomaly distribution with QBO periodicity is far more prominent in the case of NH than that in the SH (compare left and right panels on Fig. 5), which could be caused by the asymmetry of the low to middle latitude circulation anomaly (Kinnersley, 1999). He also suggested that strong cross-equatorial flow occurs near the shear zone if the zonal wind anomaly is easterly. From a plot (not shown here) of zonal winds from the NCEP/NCAR reanalysis (Kistler et al., 2001) as a function of time and latitude at $10 \mathrm{mb}$, it can be seen clearly that the latitude extent of QBO easterlies are larger in the $\mathrm{NH}$ compared to that in the $\mathrm{SH}$. Thus the $\mathrm{CH}_{4}$ anomalies in the $\mathrm{NH}$ are also larger compared to the anomalies corresponding to $\mathrm{SH}$ stratosphere. The strength of $\mathrm{CH}_{4}$ concentration change with height is in good agreement with that which has been observed for the zonal winds, forming a maximum in the middle stratosphere and diminishing to weaker speeds towards the lower and upper stratosphere (see Figs. 5 and 3). Though the NCEP/NCAR reanalysis winds as well as the model assimilated winds of the UKMO (Swinbank and O'Neill, 1994) show that the QBO signal in the zonal winds does not generally exist beyond the tropics, but the $\mathrm{CH}_{4}$ anomalies in the $\mathrm{NH}$ stratosphere do bear the QBO signal well into the midlatitudes as shown in Fig. 5. The latitude-time plot of $\mathrm{CH}_{4}$ anomaly does not decipher opposite QBO phases between the tropics and extratropics (or midlatitudes) (see also Randel et al., 1998; Dunkerton, 2001), which is contrary to observations of the $\mathrm{O}_{3}$ distribution (Randel and $\mathrm{Wu}, 1996)$.

The difference between the $\mathrm{CH}_{4}$ and ozone anomaly distribution is mainly caused by the dissimilarity in their source/sink regions, and hence the influence of stratospheric transport mechanisms. The source of $\mathrm{CH}_{4}$ in the stratosphere is located at the tropical tropopause; whereas ozone is produced largely in the middle to upper stratosphere region, spreading over a greater latitude region around the equator. The gross picture of latitude-altitude cross sections of $\mathrm{CH}_{4}$ distribution is relatively simple in the stratosphere; the mixing ratio decreases with the increase in both latitude and height. On the other hand the ozone mixing ratio decreases on either side of the equator only at the middle stratosphere, forming a peak around $10 \mathrm{mb}$ height over the tropics. While the ozone mixing ratio increases with latitude at the base as well as in the top layers of the stratosphere (Fig. 6). Thus transport of $\mathrm{O}_{3}$, in the lower and upper stratosphere (below $30 \mathrm{mb}$ and above $3 \mathrm{mb}$, respectively), due to horizontal mixing (from low to high mixing ratio) and cross-equatorial advection (tropics to extratropics) counter each other. This mechanism does not allow the in-phase QBO signal in $\mathrm{O}_{3}$ distribution to propagate much across the latitudes. The 2-D model study shows that QBO in transport and QBO in temperature dominates ozone interannual variability in the lower stratosphere and upper stratosphere, respectively (Fleming et al., 2002). The equator to midlatitude transport in the 

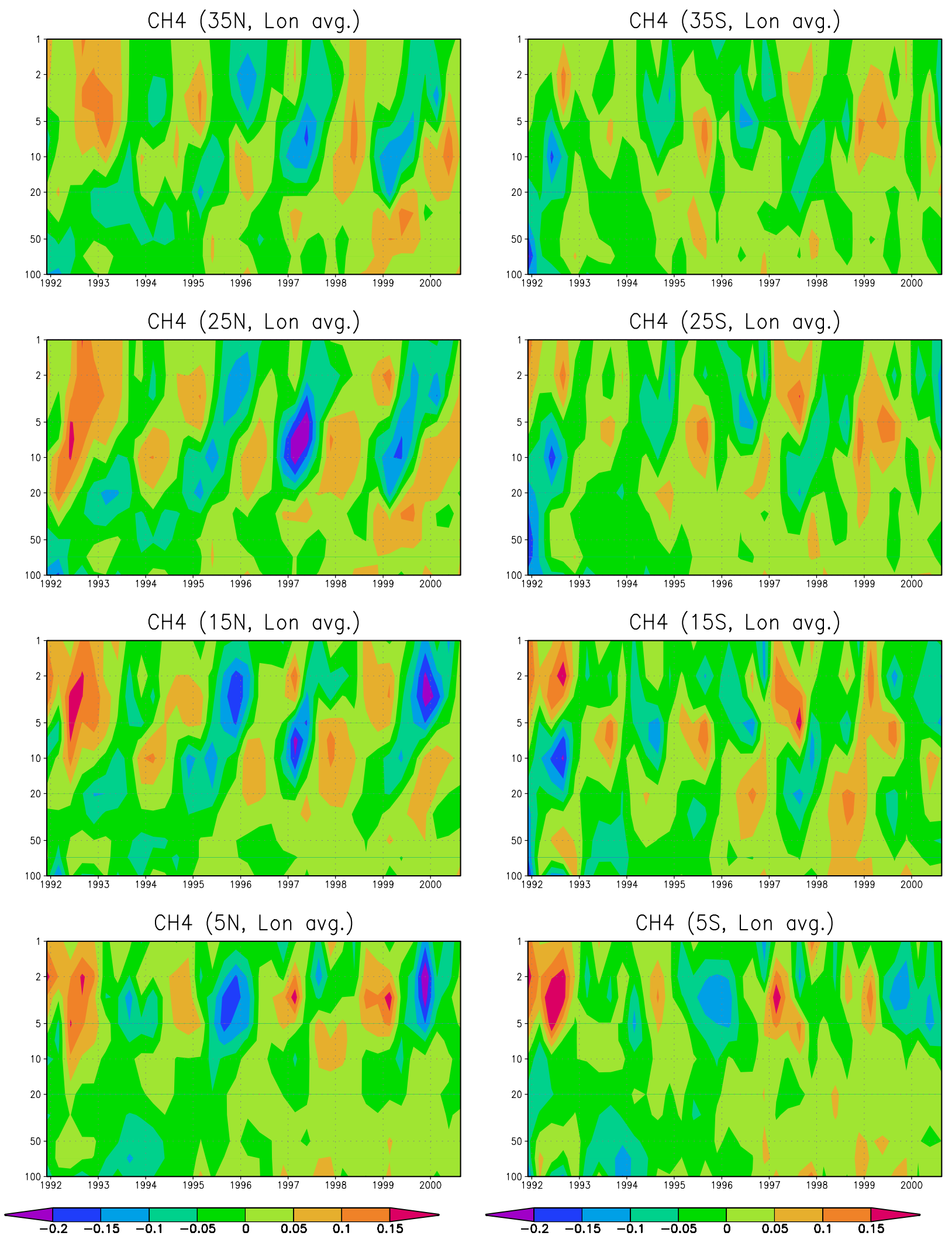

Fig. 5. Time-height variations of $\mathrm{HALOE} \mathrm{CH}_{4}$ anomalies in the stratosphere at various latitudes. Note the out-of-phase relation of $\mathrm{CH}_{4}$ anomaly in the stratosphere and zonal wind anomalies in the tropics (see Fig. 3). 


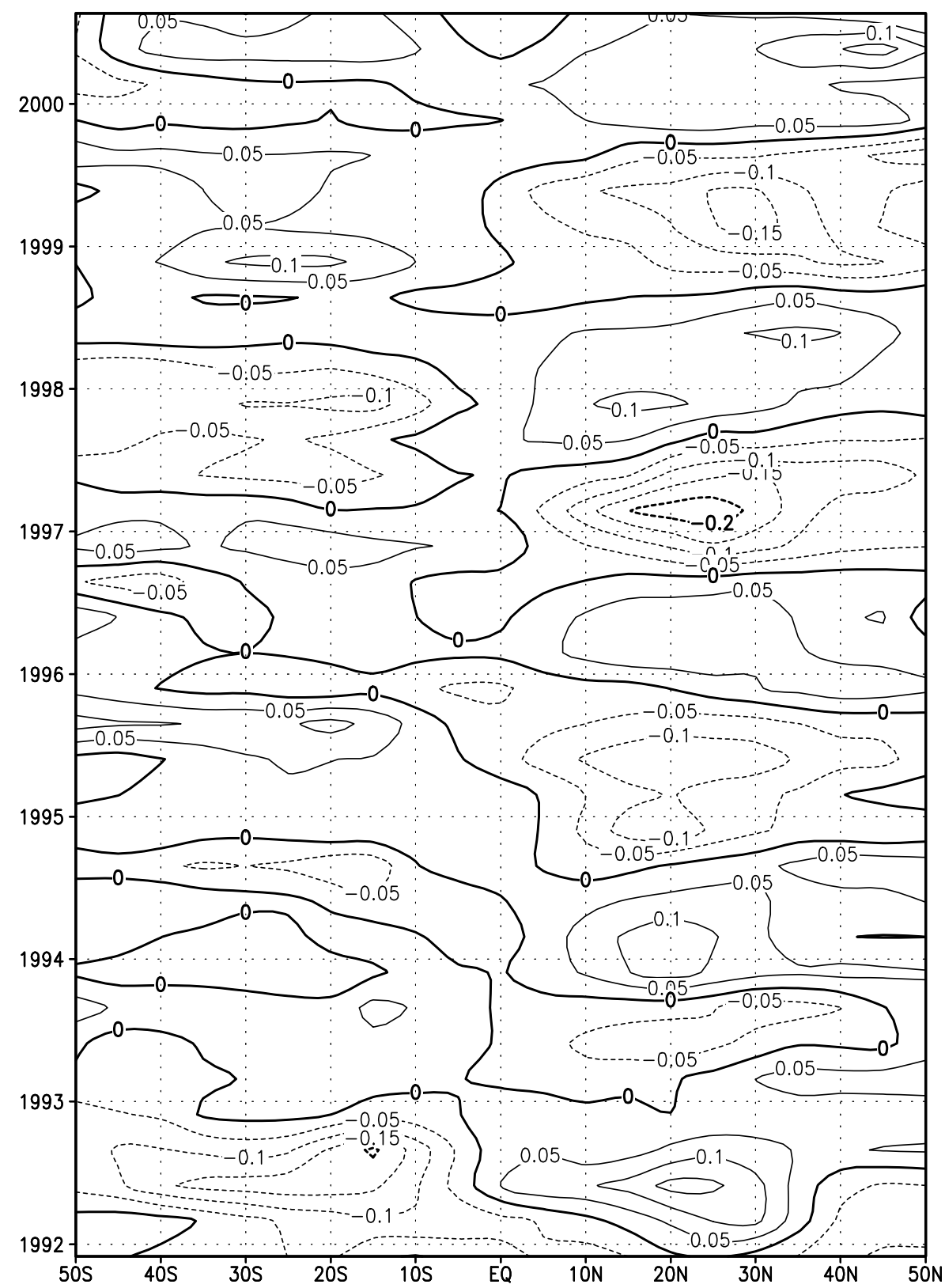

Fig. 6. Latitude-time cross section of $\mathrm{CH}_{4}$ anomaly showing the detailed latitudinal extent of QBO signal at $10 \mathrm{mb}$ pressure layer. It can be noticed that the $\mathrm{CH}_{4}$ anomalies in $\mathrm{NH}$ and $\mathrm{SH}$ are separated by a time lag of about one year.

stratosphere works quite differently for $\mathrm{CH}_{4}$ since the effects of meridional advection and horizontal mixing are additive. The distribution of aerosols adds another dimension to constrain the understanding of stratospheric transport. Hitchman and coworkers (e.g. Hitchman et al., 1994, and references therein) diagnosed tropical reservoir regions with an "upper" and "lower" transport regime, which divide the stratosphere around $22 \mathrm{~km}$ in the tropics.

The processes of stratospheric transport around the tropical region has been schematically represented in Fig. 7 during both phases of the QBO, based on the two distinct trace species, i.e. $\mathrm{CH}_{4}$ and $\mathrm{O}_{3}$, as far as their sources, sinks and distributions in the stratosphere are concerned. For this diagram we have assumed the tropical upwelling, associated with the diabatic processes (see for a review Shepherd, 2002), at the base of the stratosphere to be constant over a QBO cycle as that signal in $\mathrm{CH}_{4}$ distribution is not very strong in the lower stratosphere (ref. Fig. 5). However, the strength of the meridional transport due to advection is assumed to be variable, which is believed to be forcing the QBO signal in tracer distribution. The downwelling (lofting) during the westerly (easterly) phase of QBO wind shear 


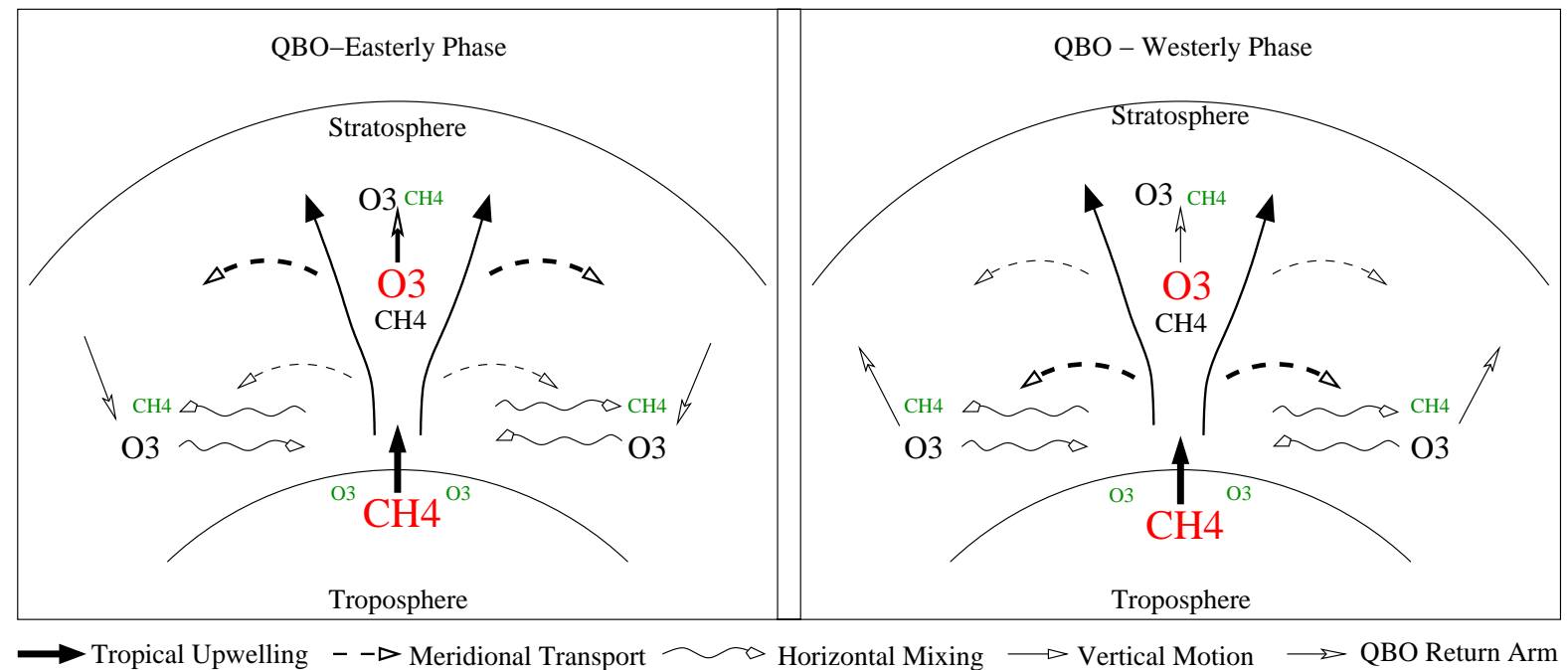

Fig. 7. Schematic diagram of the stratospheric dynamics in two phases of the QBO. Different arrows have been used to indicate prevailing dynamical components such as tropical upwelling, out of tropics (meridional) transport by the mean meridional circulation, horizontal mixing arising from the concentration gradient (from high to low), ascending (descending) QBO return arms over midlatitude during westerly (easterly) QBO phases, and the downward (upward) motion in the tropics that produce "double peak" structure in the stratosphere. The size of $\mathrm{CH}_{4}$ and $\mathrm{O}_{3}$ symbols are varied to represent areas of high to low (by big, medium and small sizes) values of mixing ratios, which in turn determines the direction of transport due to horizontal mixing. Similarly, thickness of arrow indicates the changes in strength of the meridional transport during two QBO phases.

helps to produce the prominent "rabbit ears" in the $\mathrm{CH}_{4}$ distribution in the upper stratosphere. In addition, the "return arm" of tropical QBO circulation over midlatitude, which is where the air descends (ascends) in the extratropics during the easterly (westerly) equatorial shear (Baldwin et al., 2001), is considered to produce the mid- and high latitude $\mathrm{O}_{3}$ anomaly. Thus the resulting anomaly in the subtropics is out of phase with that in the tropics. Because the $\mathrm{CH}_{4}$ mixing ratio decreases sharply with an increase in both latitude and altitude, the effect of the return arm of the equatorial QBO is not very significant (ref. Fig. 6). These transport processes in the tropics and subtropics could explain the differences in altitude and latitude variations in $\mathrm{CH}_{4}$ and $\mathrm{O}_{3}$ anomaly. This discussion is not only restricted to the trace gases alone, but is in compliance with the transport models derived from the aerosol distribution in the stratosphere (Hitchman et al., 1994). Lastly, if an analogy is drawn from the aerosol distribution in the tropics and on basis of the $\mathrm{CH}_{4}$ and $\mathrm{O}_{3}$ distributions in the stratosphere, it could be suggested qualitatively that the major part of $\mathrm{O}_{3}$ transport into the subtropics should be occurring in the middle/upper stratosphere, whereas the "out of tropics" transport of $\mathrm{CH}_{4}$ would be far more stronger in the lower part of stratosphere.

\section{Conclusions}

The comparisons between balloon-borne measurements from Hyderabad $\left(17.5^{\circ} \mathrm{N}\right)$, India in March-April months of differ- ent years in the period of 1987-1998, the HALOE/UARS measurements of $\mathrm{CH}_{4}$ during 1991-2002, and 2-D model simulations have been made. The following are the major conclusions drawn from this study:

1. The measurements from two observation techniques show good agreement in lower stratospheric mixing ratios of $\mathrm{CH}_{4}$, which are relatively less disturbed by the prevalent meteorology and largely influenced by the troposphere-stratosphere exchange. The chemistrytransport model with interannually varying meteorology also reproduces the dynamical disturbances observed in $\mathrm{CH}_{4}$ profiles.

2. In the troposphere the gradients in $\mathrm{CH}_{4}$ mixing ratio show tight anti-correlation with relative humidity at $300 \mathrm{mb}$ layer, suggesting that the vertical velocity $(\Omega)$ controls the $\mathrm{CH}_{4}$ transport from the lower troposphere to upper troposphere.

3. We show that the interannual $\mathrm{CH}_{4}$ variability in the middle stratosphere over Hyderabad during 1987, 1990, 1994 and 1998 are caused by the stratospheric dynamics, primarily governed by the quasi-biennial oscillations. In general, this relationship would provide useful information for planning the future balloon flight experiments from Hyderabad.

4. Our analysis of HALOE $\mathrm{CH}_{4}$ data suggests that the effect of QBO on the transport of tracers in the stratosphere are asymmetric across the equator and this signal 
could penetrate as deep as the midlatitudes, particularly in the northern hemisphere.

5. A mechanism for opposite $\mathrm{QBO}$ influence on $\mathrm{CH}_{4}$ and $\mathrm{O}_{3}$ mixing ratios beyond $\approx 15^{\circ}$ latitude has been described qualitatively, which is primarily arising due to the differences in their stratospheric distribution.

Acknowledgement. We appreciate the help of Y. B. Acharya, P. Rajaratnam, and G. N. Dutta for making the balloon measurement programme a success. B. H. Subbaraya has been the integral part of balloon flight programme for trace gas studies in India. We sincerely acknowledge invaluable help of the NBF personnel during the flights. The 1994 and 1998 balloon flights were funded by the ISRO-GBP, Bangalore. The HALOE/UARS $\mathrm{CH}_{4}$ data are downloaded from http://haloedata.larc.nasa.gov, and we thank all the team members for keeping the data public for scientific use. We are grateful to Charles Jackman and Eric Fleming for providing us the GSFC 2-D model results and useful discussions during the revision.

\section{References}

Baldwin, M. P., Gray, L. J., Dunkerton, T. J., Hamilton, K., Haynes, P. H., Randel, W. J., Holton, J. R., Alexander, M. J., Hirota, I., Horinouchi, T., Jones, D. B. A., Kinnersley, J. S., Marquardt, C., Sato, K., and Takahashi, M.: The quasi-biennial oscillation, Rev. Geophys., 39, 179-229, 2001.

Borchers, R., Fabian, P. Singh, O. N., Lal, S., and Subbaraya, B. H.: The vertical distribution of source gases at tropical latitudes, Proc. of the Quadrennial Ozone Symposium 1988 and Tropospheric Ozone Workshop, R. D. Bojkov and P. Fabian (Eds), A. Deepak Publishing, 290-293, 1989.

Choi, W., Lee, H., Grant, W. B., Park, J. H., Holton, J. R., Lee, K.M., and Naujokat, B.: On the secondary meridional circulation associated with quasi-biennial oscilation, Tellus, 54B, 395-406, 2002.

Dlugokencky, E. J., Walter, B. P., Masarie, K. A., Lang, P. M., and Kasischke, E. S.: Measurements of an anomalous global methane increase during 1998, Geophys. Res. Lett., 28, 499-502, 2001.

Dunkerton, T. J.: Quasi-biennial and subiennial variations of stratospheric trace constituents derived from HALOE observations, J. Atmos. Sci., 58, 7-25, 2001.

Ehhalt, D. H.: In situ observations, Phil. Trans. R. Soc. Lond. A, 296, 175-189, 1980.

Etheridge, D. M., Steele, L. P., Francey, R. J., and Langenfelds, R. L.: Atmospheric methane between 1000 A.D. and present: Evidence of anthropogenic emissions and climate variability, J. Geophys. Res., 103, 15 979-15 993, 1998.

Fabian, P.: Atmospheric Sampling, Adv. Space Res, 1, 17-27, 1981.

Fleming, E. L., Jackman, C. H., Rosenfield, J. E., and Considine, D. B.: Two-dimensional model simulation of the QBO in ozone and tracers in the tropical stratosphere, J. Geophys. Res., 107, 4465, doi:10.1029/2001JD001146, 2002.

Froidevaux, L., Waters, J. W., Read, W. G., Connell, P. S., Kinnison, D. E., and Russell, J. M.: Variations in the free chlorine content of the stratosphere (1991-1997): Anthropogenic, volcanic, and methane influences, J. Geophys. Res., 105, 4471-4481, 2000.
Hintsa, E. J., Boering, K. A., Weinstock, E. M., Anderson, J. G., Gary, B. L., Pfister, L., Daube, B. C., Wofsy, S. C., Loewenstein, M., Podolske, J. R., Margitan, J. J., and Bui, T. P.: Troposphere-to-stratosphere transport in the lowermost stratosphere from measurements of $\mathrm{H}_{2} \mathrm{O}, \mathrm{CO}_{2}, \mathrm{~N}_{2} \mathrm{O}$, and $\mathrm{O}_{3}$, Geophys. Res. Lett., 25, 2655-2658, 1998.

Hitchman, M. H., McKay, M., and Trepte, C. R.: A climatology of stratospheric aerosol, J. Geophys. Res., 99, 20 689-20 700, 1994.

Huesmann, A. S. and Hitchman, M. H.: The stratospheric quasibiennial oscillation in the NCEP reanalyses: Climatological structures, J. Geophys. Res., 106, 11 859-11 874, 2001.

Intergovernmental Panel on Climate Change (IPCC): Climate Change 1995, University Press, Cambridge, UK, 1996.

Jones, R. L. and Pyle, J. A.: Observations of $\mathrm{CH}_{4}$ and $\mathrm{N}_{2} \mathrm{O}$ by the Nimbus 7 SAMS: a comparison with in situ data and twodimensional numerical model calculations, J. Geophys. Res., 89, 5263-5279, 1984.

Jones, D. B. A., Schneider, H. R., and McElroy, M. B.: Effects of the quasi-biennial oscillation on the zonally averaged transport of tracers, J. Geophys. Res., 103, 11 235-11 249, 1998.

Kistler, R., Kalnay, E., Collins, W., Saha, S., White, G., Woollen, J., Chelliah, M., Ebisuzaki, W., Kanamitsu, M., Kousky, V., van den Dool, H., Jenne, R., and Fiorino, M.: The NCEP-NCAR 50Year Reanalysis: Monthly Means CD-ROM and Documentation, Bull. American Meteorol. Soc., 82, 247-268, 2001.

Kinnersley, J. S.: Seasonal asymmetry of the low- and middlelatitude QBO circulation anomaly, J. Atmos. Sci., 56, 1140 1153, 1999.

Lal, S., Subbaraya, B. H., Fabian, P., and Borchers, R.: Vertical distribution of $\mathrm{CH}_{4}$ and $\mathrm{N}_{2} \mathrm{O}$ over the tropical site Hyderabad, Proc. Quad. Ozone Symp. 1992, Virginia, 823-826, 1994.

Lal, S., Acharya, Y. B., Patra, P. K., Rajaratnam, P., Subbaraya, B. H., and Venkataramani, S.: Balloon-borne cryogenic air sampler experiment for the study of atmospheric trace gases, Indian J. Radio Space Phys., 25, 1-7, 1996.

Lal, S. and Sheel, V.: A study of the atmospheric photochemical loss of $\mathrm{N}_{2} \mathrm{O}$ based on trace gas measurements, Chemosphere Global Change Sci., 2, 455-463, 2000.

Lawrence, M. G., Jockel, P., and von Kuhlmann, R.: What does the global mean $\mathrm{OH}$ concentration tell us?, Atmos. Chem. Phys., 1, 37-49, 2001.

McCormak, J. P., and Siskind, D. E.: Simulation of the quasibiennial oscillation and its effect on stratospheric $\mathrm{H}_{2} \mathrm{O}, \mathrm{CH}_{4}$, and age of air with an interactive two-dimensional model, J. Geophys. Res., 107, 4625, doi:10.1029/2002JD002141, 2002.

Mote, P. W., Rosenlof, K. H., McIntyre, M. E. et al.: An atmospheric tape recorder: The imprint of tropical tropopause temperatures on stratospheric water vapor, J. Geophys. Res., 101, 3989-4006, 1996.

Patra, P. K., Lal, S., Subbaraya, B. H., Jackman, C. H., and Rajaratnam, P.: Observed vertical profile of sulphur hexafluoride $\left(\mathrm{SF}_{6}\right)$ and its atmospheric applications, J. Geophys. Res., 102, 88558859, 1997.

Patra, P. K., Lal, S., Sheel, V., Subbaraya, B. H., Bruehl, C., Borchers, R., and Fabian, P.: Chlorine partitioning in the stratosphere based on in situ measurements, Tellus, 52B, 934-946, 2000.

Patra, P. K. and Santhanam, M. S.: On the distributions and EOFs of HALOE/UARS Ozone and Methane, Eos. Trans. AGU, 82, 47, 
Fall Meet. Suppl., A41D-09, 2001.

Quiroz, R. S., Miller, A. J., and Nagatani, R. M.: A comparison of observed and simulated properties of sudden stratospheric warmings, J. Atmos. Sci., 32, 1723-1736, 1975.

Randel, W. J. and Wu, F.: Isolation of the ozone QBO in SAGE II data by singular decomposition, J. Atmos. Sci., 53, 2546-2559, 1996.

Randel, W. J., Wu, F., Russell III, J. M., Roche, A., and Waters, J. W.: Seasonal Cycles and QBO Variations in Stratospheric $\mathrm{CH}_{4}$ and $\mathrm{H}_{2} \mathrm{O}$ Observed in UARS HALOE Data, J. Atmos. Sci., 55, 163-185, 1998.

Russell III, J. M., Gordley, L. L., Park, J. H., Drayson, S. R., Hesketh, D. H., Cicerone, R. J., Tuck, A. F., Frederick, J. E., Harries, J. E., and Crutzen, P. J.: The Halogen Occultation Experiment, J. Geophys. Res., 98, 10 777-10 797, 1993.
Ruth, S., Kennaugh, R., and Gray, L. J.: Seasonal, semiannual, and interannual variability seen in measurements of methane made by the UARS Halogen Occultation Experiment, J. Geophys. Res., 102, 16 189-16 199, 1997.

Shepherd, T. G.: Issues in stratosphere-troposphere coupling, J. Meterol. Soc. Japan, 80, 769-792, 2002.

Swinbank, R. and O'Neill, A.: A stratosphere-troposphere data assimilation System, Mon. Wea. Rev., 120, 686-702, 1994.

Tung, K. K. and Yang, H.: Global QBO in circulation and ozone. Part I: Reexamination of observational evidence, J. Atmos. Sci., 51, 2699-2707, 1994. 